\title{
Statistical properties of Joule heating rate, electric field and conductances at high latitudes
}

\author{
A. T. Aikio and A. Selkälä \\ Department of Physics, University of Oulu, P.O. Box 3000, 90014, Finland
}

Received: 17 December 2008 - Revised: 13 May 2009 - Accepted: 16 June 2009 - Published: 6 July 2009

\begin{abstract}
Statistical properties of Joule heating rate, electric field and conductances in the high latitude ionosphere are studied by a unique one-month measurement made by the EISCAT incoherent scatter radar in Troms $\varnothing$ ( 66.6 cgmlat) from 6 March to 6 April 2006. The data are from the same season (close to vernal equinox) and from similar sunspot conditions (about 1.5 years before the sunspot minimum) providing an excellent set of data to study the MLT and $K_{p}$ dependence of parameters with high temporal and spatial resolution.
\end{abstract}

All the parameters show a clear MLT variation, which is different for low and high $K_{p}$ conditions. Our results indicate that the response of morning sector conductances and conductance ratios to increased magnetic activity is stronger than that of the evening sector. The co-location of Pedersen conductance maximum and electric field maximum in the morning sector produces the largest Joule heating rates 03-05 MLT for $K_{p} \geq 3$. In the evening sector, a smaller maximum occurs at 18 MLT. Minimum Joule heating rates in the nightside are statistically observed at 23 MLT, which is the location of the electric Harang discontinuity.

An important outcome of the paper are the fitted functions for the Joule heating rate as a function of electric field magnitude, separately for four MLT sectors and two activity levels $\left(K_{p}<3\right.$ and $\left.K_{p} \geq 3\right)$. In addition to the squared electric field, the fit includes a linear term to study the possible anticorrelation or correlation between electric field and conductance. In the midday sector, positive correlation is found as well as in the morning sector for the high activity case. In the midnight and evening sectors, anticorrelation between electric field and conductance is obtained, i.e. high electric fields are associated with low conductances. This is expected to occur in the return current regions adjacent to auroral arcs

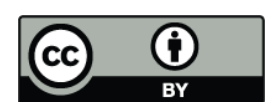

Correspondence to: A. T. Aikio (anita.aikio@oulu.fi) as a result of ionosphere-magnetosphere coupling, as discussed by Aikio et al. (2004). In addition, a part of the anticorrelation may come from polarization effects inside highconductance regions, e.g. auroral arcs. These observations confirm the speculated effect of small scale electrodynamics, which is not included in most of the global modeling efforts of Joule heating rate.

Keywords. Ionosphere (Auroral ionosphere; Particle precipitation) - Magnetospheric physics (Electric fields)

\section{Introduction}

The solar wind energy penetrating the Earth's magnetopause goes to ring current particles, plasmoids (eventually ejected away from the magnetosphere), plasma sheet heating, precipitating particles, and to Joule heating of the polar ionospheres. The role of Joule heating rate in the global energy budget has been estimated even as 50-60\% (Tanskanen et al., 2002; Østgaard et al., 2002). The global Joule heating rate estimates are typically calculated using different proxy formulas, based e.g. on magnetic activity indices like $\mathrm{AE}$ and $\mathrm{AL}$ (Ahn et al., 1983), $K_{p}$ (Foster et al., 1983), or the polar cap (PC) index (Chun et al., 1999), and on very coarse resolution data (e.g. spatial resolution of several degrees in latitude). To get exact estimates of Joule heating, global high-resolution measurements of electric fields, Pedersen conductances and E-region neutral winds should be made simultaneously. This goal is still far from being realized. The SuperDarn radars provide measurements of line-of-sight plasma velocities over a large area in the high-latitude ionosphere, which are then fitted to the IMF driven convection model (Ruohoniemi and Greenwald, 2005). SuperDarn radars are not able to provide conductance measurements. Global conductances have been calculated e.g. from auroral images made by satellites (Østgaard et al., 2002, and references therein). These

Published by Copernicus Publications on behalf of the European Geosciences Union. 


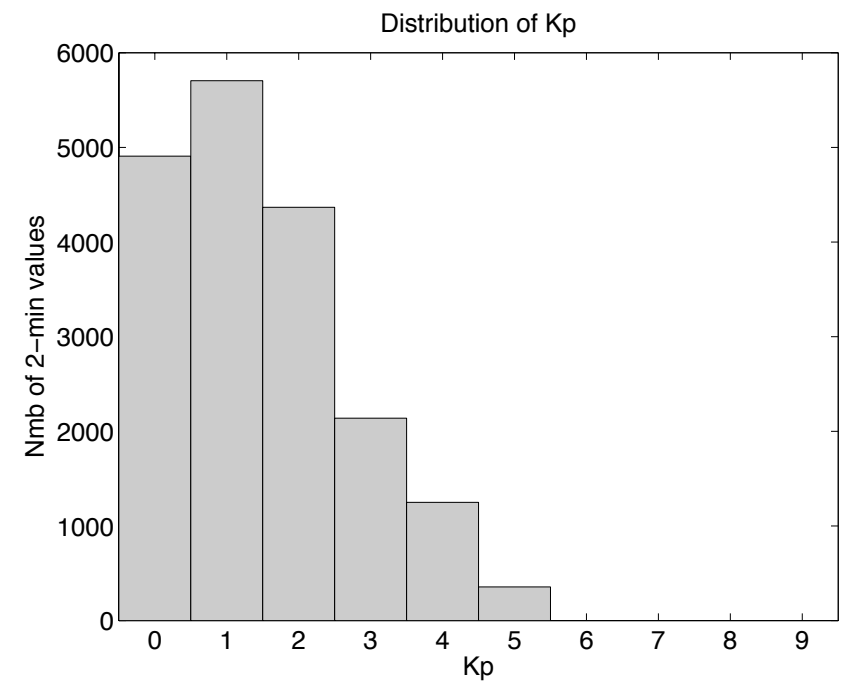

Fig. 1. Distribution of the 3-h $K_{p}$ index within the 2-min samples.

different data sets can be then combined to estimate the Joule heating rate. The AMIE method (Richmond and Kamide, 1988) is used in many Joule heating rate studies. It assimilates a diverse set of ground- and space-based observations in a least-squares sense onto a spatial grid. In locations where data do not exist, the procedure reverts to climatology.

Another approach that has been used to estimate the Joule heating rate is to calculate the Poynting flux entering the ionosphere from satellite measurements. Olsson et al. (2004) have presented fitted global Joule heating formulas under given solar illumination conditions as a function of $K_{p}, \mathrm{AE}$, the Akasofu epsilon parameter and the solar wind kinetic energy flux.

It is not known how well the global estimates represent the true Joule heating. Within the auroral oval, many smaller scale structures exist, e.g. auroral forms at various scale sizes and the associated conductance and electric field structures (e.g. Aikio et al., 2002, and references therein). It is still quite unclear, how strong Joule heating may exist within the smallest scale structures and how much they would affect the global picture. Therefore local measurements are important. The spatial resolution of the EISCAT radar at an altitude of $100 \mathrm{~km}$ (conductances) and $280 \mathrm{~km}$ (electric fields) is about 1.0 and $2.9 \mathrm{~km}$, respectively. According to Rodger et al. (2001), a poor time resolution of the electric field generally leads to underestimation of the Joule heating rate. The median of the underestimation was about $20 \%$ and the upper value $65 \%$ in the case of hourly averaged electric field versus 6-min time resolution in their study. On the other hand, Palmroth et al. (2005) argues that multiplying independent measurements of averaged electric fields and Pedersen conductances yields an overestimation of Joule heating. In this study, we use a temporal resolution of $2 \mathrm{~min}$.
Simultaneous measurements of electric fields and conductances from the same magnetic field line can be made with incoherent scatter radars. Such studies have mainly been event studies and only few studies with larger statistics are found from the literature. We will compare our electric field and conductance estimates to the results by Davies and Lester (1999) and Sugino et al. (2002), who have used EISCAT measurements from a large data base. The two studies have not estimated Joule heating rates but calculated ionospheric currents. Kosch and Nielsen (1995) utilized STARE and SABRE radar measurements together with a conductance model to get statistics of Joule heating rates.

The role of E-region neutral winds in the transfer of electromagnetic energy can be substantial at times. The estimates made by incoherent scatter radar measurements by Thayer (1998) and Fujii et al. (1999) suggest that up to $10-30 \%$ or on the average $35 \%$, respectively, of the total electromagnetic energy entering the ionosphere goes to mechanical energy of the neutral wind and the rest to Joule heating. When the neutral wind acts as a dynamo, it can be a source of electromagnetic energy, too. In this study we have no neutral wind measurements available and therefore we estimate the Joule heating rate by using the electric field measured in the coordinate system fixed to the earth, not to the neutrals.

\section{Methods}

The data are obtained from the Troms $\varnothing$ EISCAT UHF radar (geographic: $69.59^{\circ} \mathrm{N}, 19.22^{\circ} \mathrm{E}, \operatorname{cgm}$ : $66.58^{\circ}, 102.94^{\circ}$ ) pointing in the field-aligned direction in the $\mathrm{CP} 1$ experiment from 6 March 12:00 UT to 6 April 2006 12:00 UT providing altogether 25 full measurement days ( 2 weekends, 11-12 and 18-19 March are missing). The measurement is based on alternating codes and it gives altitude profiles of electron density and electron and ion temperatures. The electric field is obtained from the tri-static measurement in the F-region (Risbeth and Williams, 1985). In the measurement, three independent components of the ion velocity vector are obtained by the three receiving antennas (in Troms $\varnothing$, Kiruna and Sodankylä) from a common volume at an altitude of $280 \mathrm{~km}$. Those are combined to a vector by a suitable geometry matrix. At the measurement altitude, plasma is drifting at the $\boldsymbol{E} \times \boldsymbol{B}$-velocity and hence the plasma velocity can be converted to electric field by using the IGRF-model of magnetic field.

The data were integrated in the analysis for a set of postintegration times and the 2-min values gave sufficiently low error values for the electric fields, so it was selected. As high as possible temporal resolution is important, since longer integration times correspond to larger spatial scales, which may lead to underestimation of Joule heating rates.

The calculation of Pedersen and Hall conductivity altitude profiles is performed by utilizing the measured electron density profiles by the EISCAT UHF radar looking in 


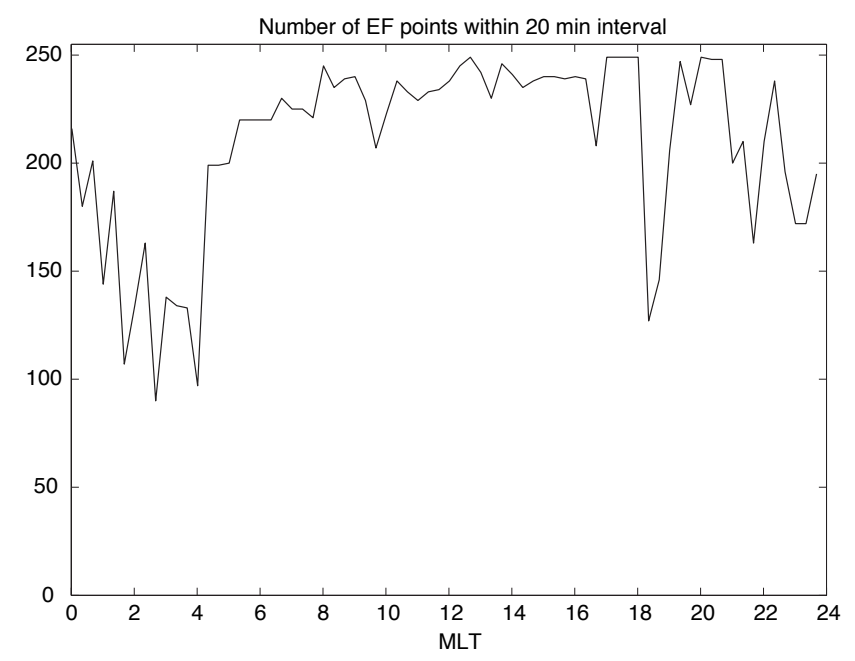

Fig. 2. Number of 2-min samples used in 20-min windows of electric field and Joule heating MLT plots.

the field-aligned direction and using standard equations with two dominant ion species (combined $\mathrm{NO}^{+}$plus $\mathrm{O}_{2}^{+}$ion and $\mathrm{O}^{+}$), whose relative proportion changes with altitude (e.g. Brekke and Hall, 1988; Davies and Lester, 1999; Moen and Brekke, 1990). The ion-neutral and electron-neutral collision frequencies are calculated according to Brekke and Hall (1988), and the required neutral parameters are taken from the NRLMSISE-00 model (Picone et al., 2002). The conductivity profiles are then height-integrated between altitudes of 70 and $330 \mathrm{~km}$. We calculate the height-integrated Joule heating rate (from now on simply the Joule heating rate) from equation $q_{j}=\boldsymbol{j} \cdot \boldsymbol{E}=\boldsymbol{\Sigma}_{P} E^{2}$, where $\boldsymbol{j}$ is the heightintegrated current density, $\boldsymbol{\Sigma}_{P}$ is the height-integrated Pedersen conductivity and $\boldsymbol{E}$ is the electric field measured in the coordinate system fixed to the earth, since we have no measurements of the wind velocity profile.

The 3-h planetary $K_{p}$ index is used to describe the global activity level. Figure 1 shows the distribution of values during the studied time period. In the following, we have divided the data into two parts: low activity corresponding to values $K_{p}=0-2+$ and higher activity (hereafter referred to as high activity), corresponding to values $K_{p}=3--5$. It is clear that the period is dominated by quiet days with the ratio of low activity periods to high activity periods of $4: 1$.

The diurnal plots shown are further averaged to 20-min intervals from the original 2-min resolution to get better statistics (e.g. Fig. 3). Thus, for each point, maximum of $25 \times 10=250$ samples are obtained within the 20-min window. This is the case for the conductance estimates, which are calculated from the measured electron density profiles by the Troms $\varnothing$ receiver. For electric fields, strong enough signal from each of the three receiving stations is needed. For very low F-region densities, the SNR at the remote stations gets very low and the analysis fails. We tried to further rule

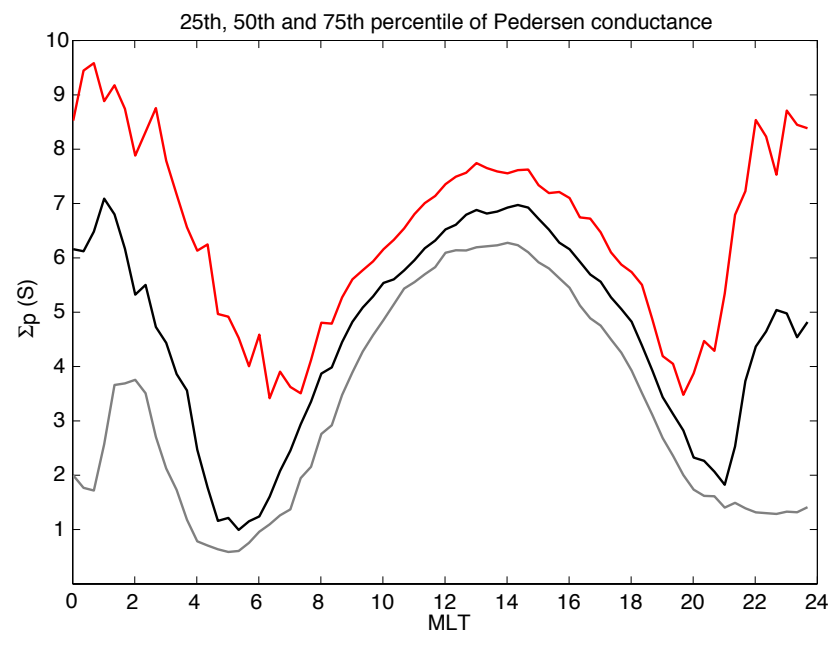

Fig. 3. Pedersen conductance: the median is shown as a black curve, and the lower and upper quartiles are shown in grey and red, respectively.

out unreliable points by using a condition that the error in electric field may be $40 \mathrm{mV} \mathrm{m}^{-1}$ at maximum. It is possible that a couple of true large electric fields were lost as well, but not too many (we have made a quick visual inspection of ion temperature during the days, which should be increased for large electric fields). The number of electric field estimates in the 20-min window as a function of MLT is shown in Fig. 2 and it can be seen that smallest number of samples come from the morning sector 01-04 MLT.

\section{Results and discussion}

\subsection{MLT variation of conductances}

Figure 3 shows the height-integrated Pedersen conductivity as a function of magnetic local time (MLT). The solar EUVproduced conductance enhancement peaks at about 14 MLT. For the median curve (50th percentile), minima are observed at 05 and $21 \mathrm{MLT}$, whereas the upper quartile (75th percentile) has minima somewhat later and earlier, respectively. The lower quartile (25th percentile) has no pre-midnight enhancement at all. The median Pedersen conductance in the pre-midnight sector is $5 \mathrm{~S}$ and the maximum of $7 \mathrm{~S}$ is observed at about 01 MLT.

Figure 4 shows how the statistics of Pedersen conductance are affected by low $\left(K_{p}<3\right.$, blue curves) and high activity ( $K_{p} \geq 3$, red curves). The low-activity curve has a resolution of $20 \mathrm{~min}$. To get more statistical weight for active conditions $\left(K_{p} \geq 3\right)$, we use the resolution of $60 \mathrm{~min}$. Thus the relationship 3:1 in time window between the high and low activity data compensates to a large extent the ratio $1: 4$ in the $K_{p}$ conditions. The thick curves represent median values and in addition, we show the quartiles (thin blue lines 


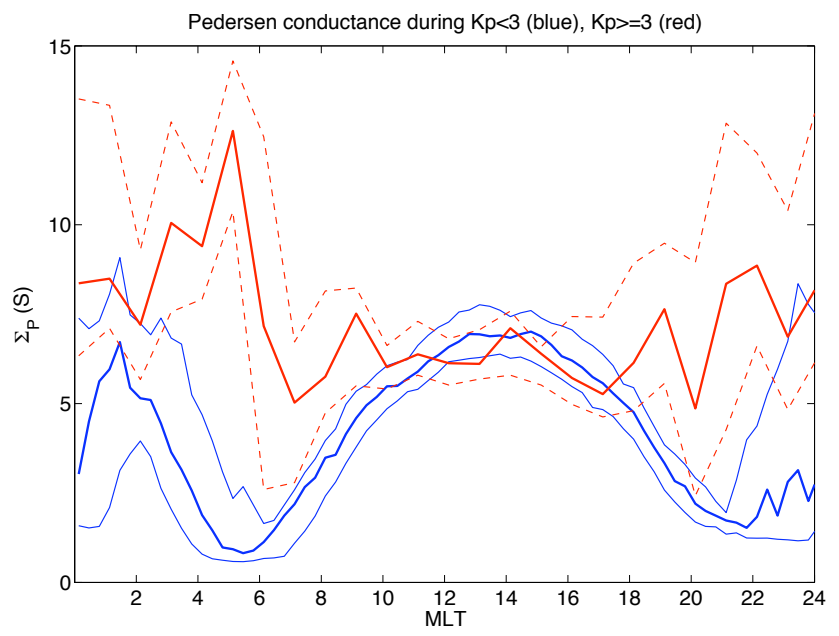

Fig. 4. Pedersen conductance for $K_{p}<3$ (blue) and for $K_{p} \geq 3$ (red). Thick lines indicate median values. The lower and upper quartiles are shown by thin blue lines for $K_{p}<3$.

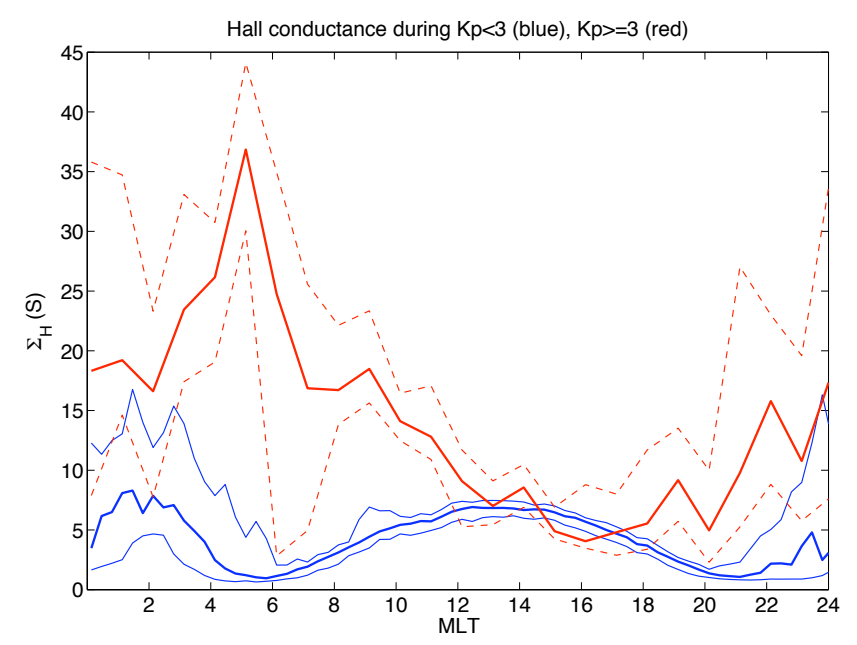

Fig. 5. Hall conductance in the same format as Fig. 4.

for low-activity case and thin red dashed curves for the highactivy case). The low activity curves resemble the median curve in Fig. 3 showing a single nightside enhancement with a maximum at 01 MLT. As activity increases, the Pedersen conductance enhancement expands toward west and east and the maximum in the morning shifts clearly to a later time, to 05 MLT where it reaches $13 \mathrm{~S}$.

The Hall conductance curves resemble those of the Pedersen conductance in shape (Fig. 5). In particular, high magnetic activity enhances the Hall conductance (red curve) in the morning sector, producing a clear maximum up to $37 \mathrm{~S}$ at 05 MLT. High values extend to very late morning hours. Hence, during active conditions the Hall to Pedersen conductance ratio (Fig. 6) reaches its maximum at 08 MLT with a value of 3 . Values above 2 prevail in the whole morning sector until 11 MLT.

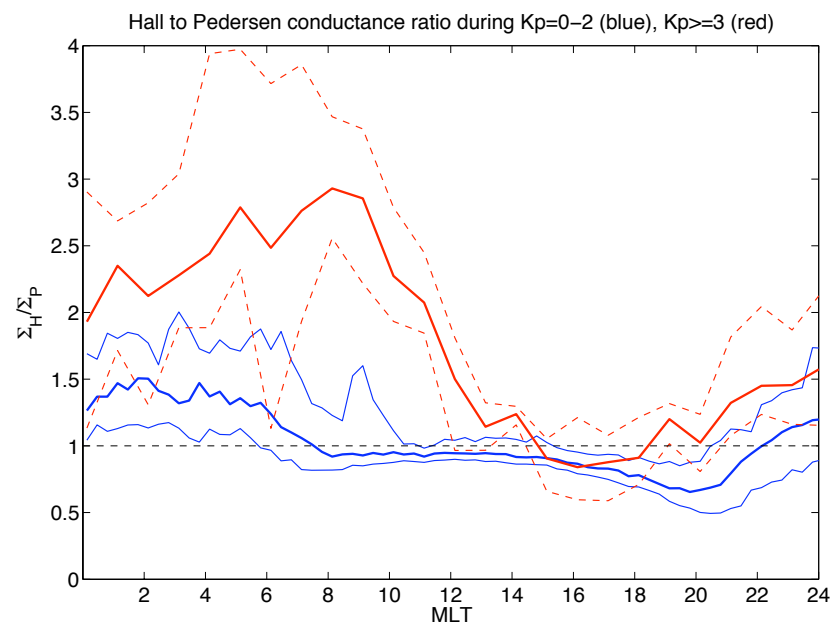

Fig. 6. Hall to Pedersen conductance in the same format as Fig. 4.

The low activity median of Hall to Pedersen conductance ratio is close to 1.0 during midday but becomes less than 1.0 in the afternoon and evening hours. A clear minimum is observed at 20 MLT for the median and lower quartile curves, when values as low as 0.5 can be reached. The median becomes larger than 1.0 at 22 MLT and increases up o 1.2 at midnight. A flat maximum of 1.5 is observed post-midnight with quartile values of 1.25 and 1.75 .

The conductance and electric field estimates will be compared with the results by Davies and Lester (1999) and Sugino et al. (2002), since both are based on EISCAT measurements. The data base of Davies and Lester (1999) is slightly larger than ours and it is collected over years 1992-1997, from close to sunspot maximum down to the minimum. Data are not sorted according to activity level. When making the comparison, we have changed the UT values by Davies and Lester to MLT by adding $2.5 \mathrm{~h}$ to UT. The data utilized by Sugino et al. (2002) are based on 10 years of EISCAT measurements (from 228 days), so it covers both solar minimum and maximum conditions. Their data resolution varies between 2 and $10 \mathrm{~min}$ and the data are sorted according to $K_{p}$.

Davies and Lester (1999) find rather flat Pedersen conductance maxima between 18 and 04 MLT. The Hall conductance shows asymmetry between evening and morning with a morning maximum at about 04 MLT, in agreement with our data of active conditions. An interesting feature in their data set is a minimum in conductances at about 01:30 MLT, visible in particular in the upper quartile of Hall conductance. The average MLT-curves of conductances by Sugino et al. (2002) show rather flat maxima in the night side with increased values as the $K_{p}$ value increases. So, the morning Pedersen maximum during active conditions, observed in this study, is not well visible in the aforementioned studies.

Senior (1991) has extracted the conductance curves for the latitude of Troms $\emptyset$ from the statistical model by Hardy et al. 


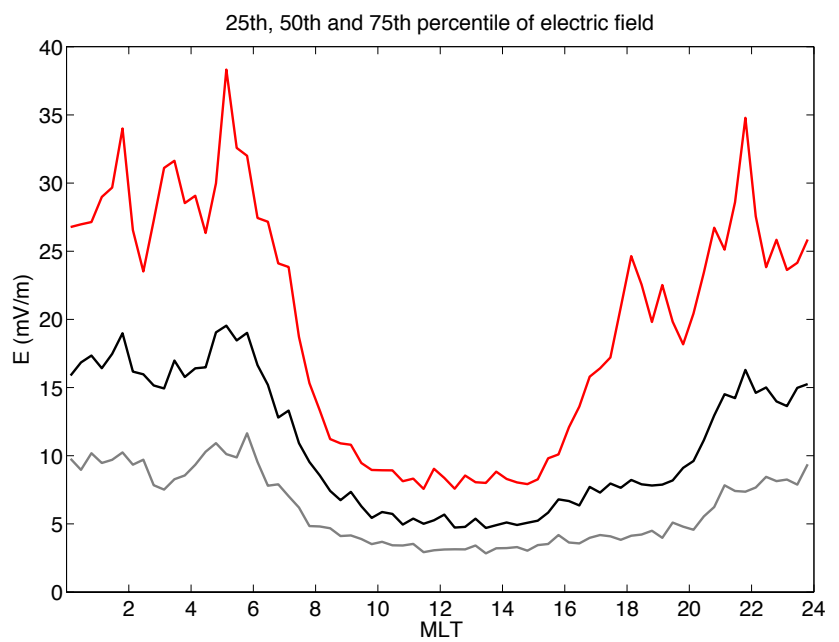

Fig. 7. Total electric field, same format as Fig. 3.

(1987). The statistical model is based on DMSP measurements of precipitating electrons and an equation assuming isotropic Maxwellian electron fluxes to produce the conductances. The $K_{p}=3$ and $K_{p}=4$ Hall conductance curves have a maximum at 05 MLT in accordance with our curve for $K_{p} \geq 3$ (Fig. 5, red curve). However, the value of the morning maximum in Hardy model just barely exceeds the evening values. The Pedersen conductance has a small local maximum at 05 MLT for $K_{p}=4$, but it isn't the largest value.

The values of conductances are of interest, too. In the study by Davies and Lester (1999), the average Pedersen conductances of all data are very close to those of Fig. 3 and the maxima of average Hall conductances are 10 and $15 \mathrm{~S}$ for evening and morning, whereas in our study they are slightly smaller (6 and $11 \mathrm{~S}$, figure not shown). However, the median Pedersen and Hall conductance values for $K_{p} \geq 3$ in our study are higher than those of $K_{p}=4$ by Hardy et al. (1987). In the pre-midnight sector, the difference is only a few Siemens, but in the morning sector the difference is very large: our Hall and Pedersen maxima are 37 and 13 S, respectively, whereas in the Hardy model the maxima are 16 and $8 \mathrm{~S}$. There can be at least three explanations: the poor spatial resolution ( $1^{\circ}$ lat and $0.5 \mathrm{~h} \mathrm{MLT)}$ by Hardy et al. (1987), their assumption of Maxwellian spectra, and seasonal averaging.

The conductance ratio by Davies and Lester (1999) doesn't show such a clear pattern as this study, and the ratio for the lower quartile stays always above 1.0. Davies and Lester (1999) find the maximum conductance ratio at about 09 MLT, which is rather close to the maximum time of 08 MLT of this study for $K_{p} \geq 3$ (Fig. 6).

The Hall to Pedersen conductance ratio is estimated from the vector magnetic data measured with the CHAMP satellite in the study by Juusola et al. (2007). The statistics from 2001 to 2002 show several interesting features. First, when the magnetic activity level changes from quiet through moderate

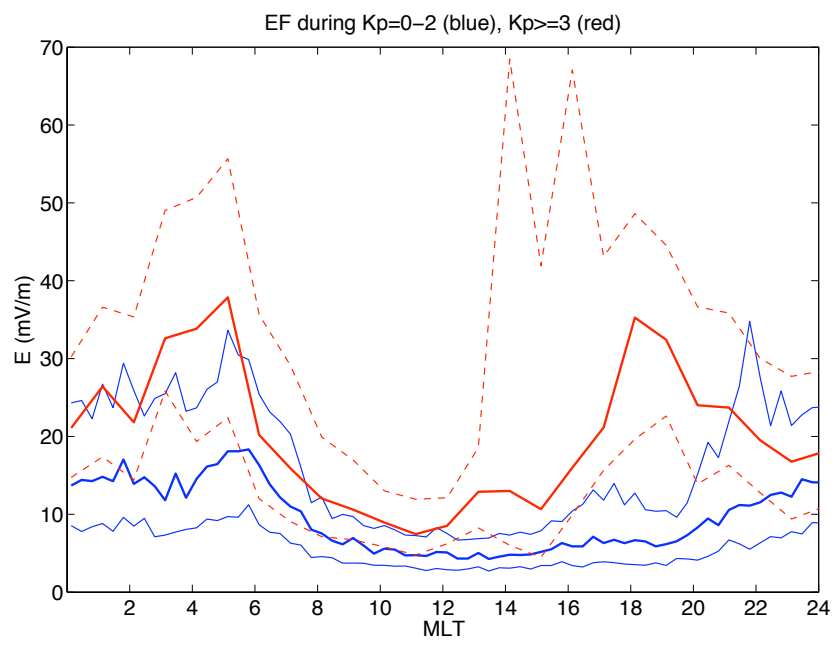

Fig. 8. Total electric field, same format as Fig. 4.

to active, it can be seen that only during active conditions the morning sector conductance ratio is clearly higher than that in the evening sector. Second, when the data is sorted into winter, equinox and summer conditions, the morning sector ratio is much higher than the evening sector ratio in the winter, a clear difference exists still in the equinox conditions, but during summer the ratios are equal. The maximum values of the ratio remain below 2 in the estimates by Juusola et al. (2007), but in this study we find that the morning equinox conductance ratio during active conditions is mainly between 2 and 3.

\subsection{MLT variation of electric field}

Figure 7 shows the total electric field. The median is low during day and early evening, starts to increase at 20 MLT and reaches a maximum of $16 \mathrm{mV} \mathrm{m}^{-1}$ at 22 MLT. The median is rather flat in the night sector and after a maximum of $18 \mathrm{mV} \mathrm{m}^{-1}$ at 05:30 MLT it starts to decrease. The upper quartile shows a more pronounced maximum of $35 \mathrm{mV} \mathrm{m}^{-1}$ at 22 MLT, a local minimum at 23 MLT and high postmidnight values with a maximum of $38 \mathrm{mV} \mathrm{m}^{-1}$ at $05 \mathrm{MLT}$. A clear difference between the median an upper quartile is observed between 16 and 20 MLT, where the upper quartile shows and additional maximum at 18 MLT.

To get more insight into the electric field, we show Figs. 8 10. Figure 8 shows that at all curves in the morning sector maximize at about 05 MLT. In the evening sector, the upper quartile of the low activity level has a maximum at 22 MLT, the median of the high activity level at 18 MLT and the upper quartile of the high activity level 14-16 MLT. The results are in accordance with Sugino et al. (2002), who show that with increasing $K_{p}$, the evening maximum of the electric field shifts to an earlier time and the morning maximum to a later time (we see the change only in the evening sector). At least 


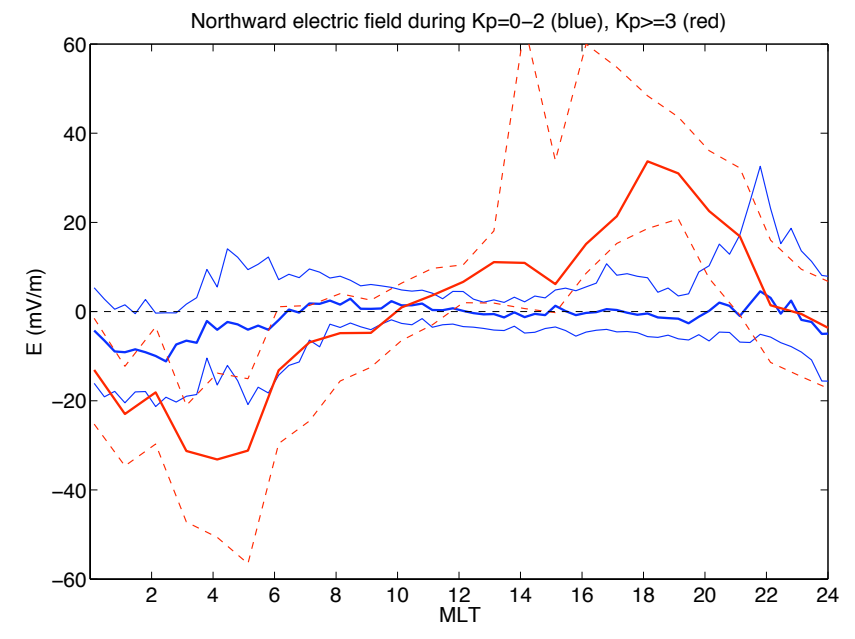

Fig. 9. Electric field northward component in geomagnetic coordinates, same format as Fig. 4.

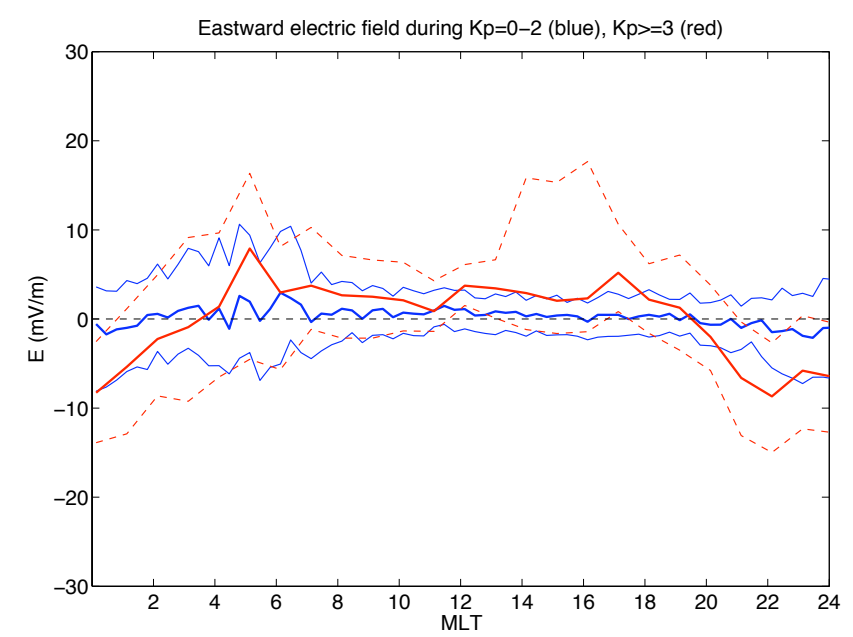

Fig. 10. Electric field eastward component in geomagnetic coordinates, same format as Fig. 4.

part of this effect may be due to expansion of the convection pattern to lower latitudes as activity increases and then the measurement site (Troms $\emptyset$ ) crosses the equatorward boundary of the auroral oval at earlier (later) MLT when rotating from the dayside (nightside) to night (day).

Figure 9 shows the northward electric field in local geomagnetic coordinates. The low-activity median (blue curve) is positive between 20 and 23 MLT and negative between 23 and 07 MLT, corresponding to the evening northward and morning southward convection electric field, respectively. The upper quartile reaches $30 \mathrm{mV} \mathrm{m}^{-1}$ at 22 MLT and the lower quartile $20 \mathrm{mV} \mathrm{m}^{-1}$ at $02 \mathrm{MLT}$. During high activity, the northward electric field (red median curve) prevails in the whole evening sector extending to 10 MLT on the dayside. Maximum occurs at 18 MLT. The field turns south-

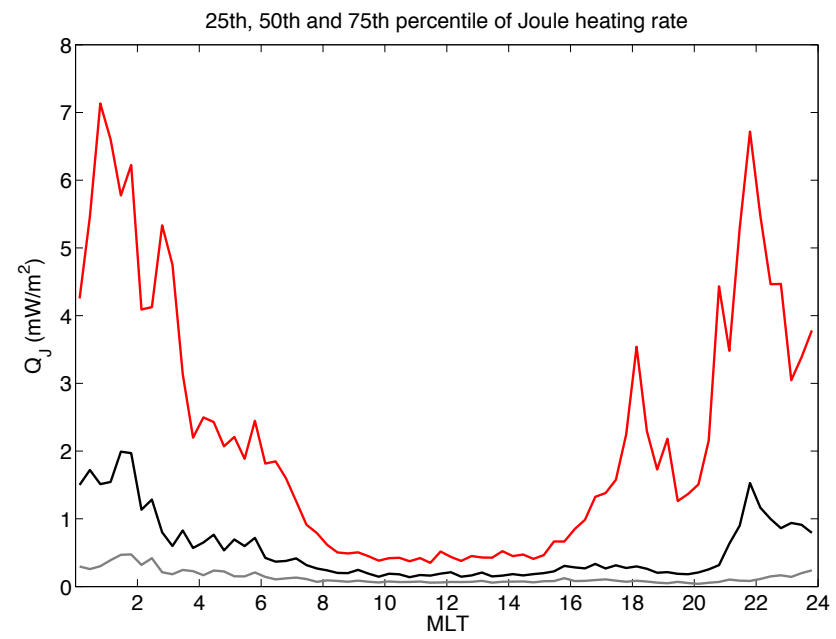

Fig. 11. Joule heating rate, same format as Fig. 3.

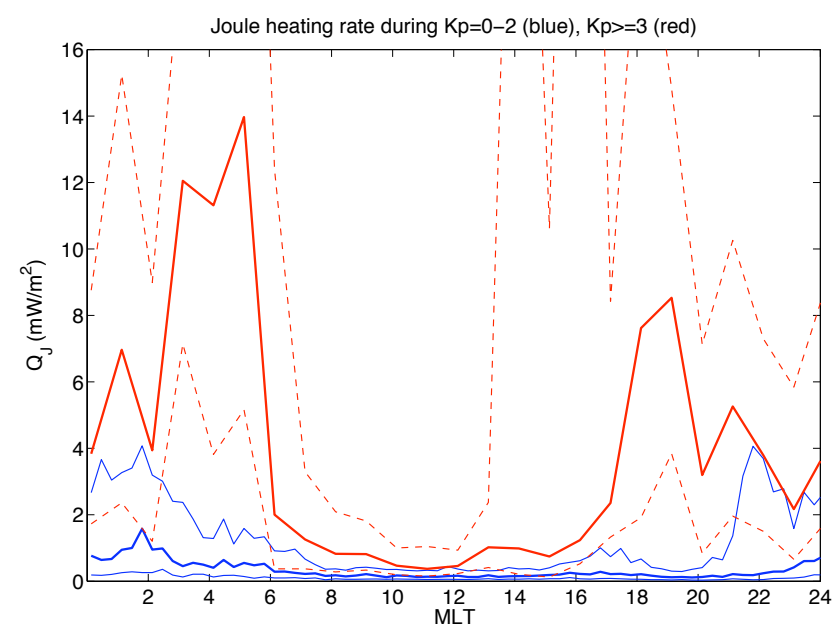

Fig. 12. Joule heating rate, same format as Fig. 4.

ward at 23 MLT and the morning maximum is encountered at 04 MLT. The values of evening and morning maxima in the median curve are equal and about $35 \mathrm{mV} \mathrm{m}^{-1}$. The upper and lower quartile absolute values of the northward electric field (red dashed curves) reach $60 \mathrm{mV} \mathrm{m}^{-1}$ and they shift to an earlier time in evening and to a later time in the morning as compared to the median, in good accordance with Sugino et al. (2002).

The convection reversal, i.e. the electric Harang discontinuity, occurs at about 23 MLT for both $K_{p}<3$ and $\mathrm{K}_{p} \geq 3$. The Harang discontinuity takes place at 23 MLT in Sugino et al. and at 22:30 MLT for the median curve in Davies and Lester (1999), so all these studies agree.

The azimuthal component of the electric field in Fig. 10 stays below $10 \mathrm{mV} \mathrm{m}^{-1}$ and it is westward in the midnight sector between 20 and 04 MLT, eastward at other times. Also this component is in agreement with the results by Sugino 
et al. (2002). In the study by Davies and Lester (1999), the westward electric field changes a couple of hours earlier eastward in the morning sector.

\subsection{MLT variation of Joule heating rate}

Figure 11 shows the Joule heating rate. By comparing to Fig. 7, it is quite clear that the pre-midnight maxima (22 MLT for the median and 18 and 22 MLT for the upper quartile) correspond to maxima in electric field (northward component). In the post-midnight sector, the variation of Joule heating doesn't resemble that of the electric field, but that of the Pedersen conductance in Fig. 3. The maximum occurs 0102 MLT for the median and at 01 MLT for the upper quartile, which correspond to times of Pedersen conductance maxima. The values are low, with maxima of 2 and $7 \mathrm{~mW} \mathrm{~m}^{-2}$ for the median and the upper quartile, respectively.

Figure 12 shows the Joule heating rate for high and low activity levels. The diurnal variation of the upper quartile of low activity curve (thin blue line) follows that of the median curve in Fig. 11, with twice as high values. The high activity median (red line) is very different and has an evening maximum at 19 MLT of $8 \mathrm{~mW} \mathrm{~m}^{-2}$ and a morning maximum at 05 MLT reaching $14 \mathrm{~mW} \mathrm{~m}^{-2}$. The upper quartile reaches values as high as $50 \mathrm{~mW} \mathrm{~m}^{-2}$ (not shown). A common feature in the high activity median and low activity upper quartile is a minimum at about 23 MLT. This is due to the minimum in the total electric field at that time.

To check the relative roles of Pedersen conductance and the total electric field in Joule heating, we show Fig. 13 for $K_{p} \geq 3$. The figure reveals that the evening maximum 18-19 MLT is associated with an electric field maximum, whereas the morning maximum 03-05 MLT is associated with both the electric field and Pedersen conductance maximum.

Kosch and Nielsen (1995) have made a statistical study of Joule heating rates by using two coherent scatter radars, STARE (f-o-v located in vicinity of EISCAT) and SABRE, during 1982-1986 covering the declining phase of a sunspot cycle. The total number of days is 173 in their study and most of the data come from $3 \leq K_{p} \leq 5$. This is mostly due to the threshold electric field of the order of $25 \mathrm{mV} \mathrm{m}^{-1}$ needed to excite observable instabilities. Conductances are taken from a model. The result is a rather smooth curve of Joule heating with a broad evening maximum between about 15 and 20 MLT of about $8 \mathrm{~mW} \mathrm{~m}^{-2}$, then a plateau at a level of $4 \mathrm{~mW} \mathrm{~m}^{-2}$ and an increase starting at about 22 MLT until the peak of $18 \mathrm{~mW} \mathrm{~m}^{-2}$ at about 03:30 MLT. After that, the Joule heating rate decreases rapidly, much like the upper quartile in Fig. 11 of this paper. The smoothness in curves by Kosch and Nielsen (1995) may be partly due to combining data from two radars with MLTs separated by $1 \mathrm{~h}$ to a presentation as a function of UT. However, their values are rather close to $K_{p} \geq 3$ values in Fig. 12 of this paper.

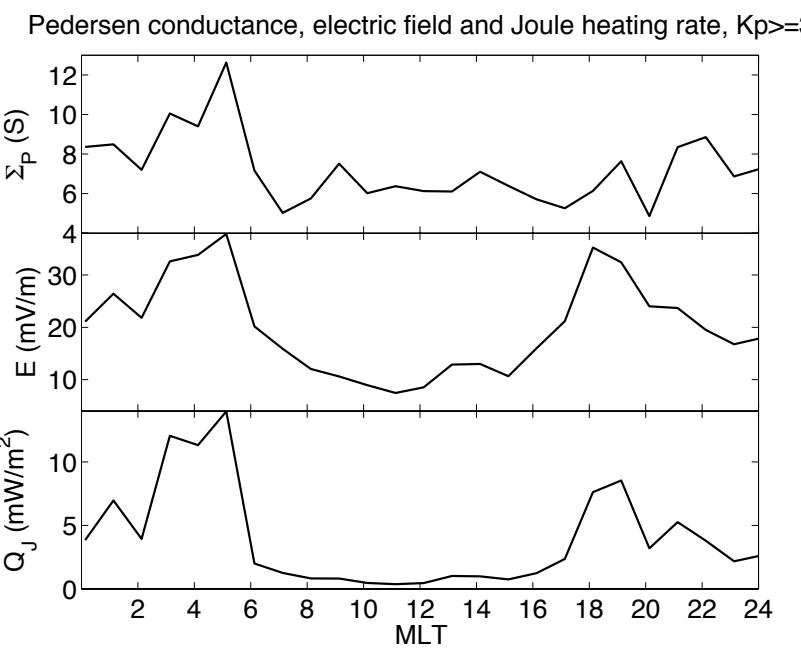

Fig. 13. Median curves of Pedersen conductance (top), total electric field (middle) and Joule heating rate (bottom) for $K_{p} \geq 3$.

Weimer (2005) has modeled the Joule heating rate as a function of the IMF direction. He combines models of fieldaligned currents (FACs) and electric potentials to calculate the Joule heating rate in the ionosphere. The ionospheric conductivity is implicitly contained within the FAC model data. In the absence of a southward component of the IMF, Joule heating rates remain below about $7 \mathrm{~mW} \mathrm{~m}^{-2}$. For a pure southward IMF, a maximum of $19 \mathrm{~mW} \mathrm{~m}^{-2}$ is found, and with an additional $B_{y}$ positive or negative, maxima are 15 and $13 \mathrm{~mW} \mathrm{~m}^{-2}$, respectively. These values are very close to the morning maximum value presented in Fig. 12. However, in this study the evening sector values are clearly smaller than the morning sector values during active conditions, whereas in the study by Weimer, maximum values are equally large, or the evening maximum is slightly larger. We suggest that the difference originates from the Pedersen conductance: in our study the morning sector conductances are clearly higher than those in the evening sector, whereas the electric field magnitudes are equal.

Statistical studies of global Joule heating rates have been made also by using the AMIE (Assimilative Mapping of Ionospheric Electrodynamics) procedure. The AMIE technique is a weighted least-squares fit of ionospheric electrodynamic parameters to a variety of ground- and space-based data and statistical models. The study by McHarg et al. (2005) is based on AMIE procedure and it shows very strong morning dominance of Joule heating during active conditions (classified by the IMF magnitude) with a maximum during 03-06 MLT, in accordance with our results, even though the difference between morning and evening is not as pronounced in our data. In the evening sector, their model produces the maximum about two hours earlier than this study. The AMIE study by Chun et al. (2002) shows some asymmetry between morning and evening as activity increases (sorted 
Table 1. Joule heating rate $q_{j}$ (in units of $\mathrm{W} \mathrm{m}^{-2}$ ) as a function of total electric field $E$ (in units of $\mathrm{V} \mathrm{m}^{-1}$ ).

\begin{tabular}{lllll}
\hline & \multicolumn{3}{c}{$K_{p}<3$} & \multicolumn{2}{c}{$K_{p} \geq 3$} \\
MLT & $E<25 \mathrm{mV} \mathrm{m}^{-1}$ & $E \geq 25 \mathrm{mV} \mathrm{m}^{-1}$ & $E<25 \mathrm{mV} \mathrm{m}^{-1}$ & $E \geq 25 \mathrm{mV} \mathrm{m}^{-1}$ \\
\hline 09:00-15:00 & $q_{J}=5.4 E^{2}$ & $q_{J}=9.1 E^{2}-0.12 E$ & $q_{J}=6.4 E^{2}$ & $q_{J}=10.6 E^{2}-0.17 E$ \\
15:00-21:00 & $q_{J}=5.3 E^{2}-0.01 E$ & $q_{J}=3.9 E^{2}+0.10 E$ & $q_{J}=9.6 E^{2}-0.05 E$ & $q_{J}=7.8 E^{2}-0.03 E$ \\
21:00-03:00 & $q_{J}=6.9 E^{2}-0.03 E$ & $q_{J}=2.5 E^{2}+0.11 E$ & $q_{J}=10.4 E^{2}-0.01 E$ & $q_{J}=5.1 E^{2}+0.15 E$ \\
03:00-09:00 & $q_{J}=3.0 E^{2}$ & $q_{J}=1.7 E^{2}+0.01 E$ & $q_{J}=8.7 E^{2}-0.03 E$ & $q_{J}=11.9 E^{2}-0.08 E$ \\
\hline
\end{tabular}

by the PC-index), but not as clear as the paper by McHarg et al. However, in Chun et al. the evening maximum is at about 18 MLT as in our study for active conditions. The location of morning maximum is in accordance with this study, too.

An interesting feature in the study by Weimer (2005) is a gap in Joule heating (values below $2 \mathrm{~mW} \mathrm{~m}^{-2}$ ) during $22-$ 01 MLT ( $B_{y}$ negative) or 21-00 MLT ( $B_{y}$ positive) within the oval for the southward IMF. We don't find such a clear gap, but median values during active conditions go below $4 \mathrm{~mW} \mathrm{~m}^{-2}$ during 22-00 MLT with a minimum at 23 MLT, mostly due to a minimum in total electric field. A minimum in Joule heating rate during active conditions between roughly 21 and 00 UT is found also by Chun et al. (2002).

\subsection{Joule heating rate vs. electric field in different MLT sectors}

Since measurements of electric fields are obviously more often available than measurements of conductances, it is of interest to study whether the Joule heating rate could be expressed as a function of electric fields. We have approached this problem by dividing data into four MLT sectors: midday (09:00-15:00 MLT), evening (15:00-21:00 MLT), midnight (21:00-03:00 MLT) and morning (03:00-09:00 MLT). In addition, we separate the data into low $\left(K_{p}=0-2\right)$ and high activity $\left(K_{p}=3-5\right)$ parts, as in the previous section.

Because $q_{j}=\Sigma_{P} E^{2}$, it would be natural to try to make a fit of that type, but we also allow a linear relationship in the fit, so that the fitted function is $q_{j}=A E^{2}+B E$, where $A$ and $B$ are the fitted parameters. We don't include a constant in the equation, since when electric field is zero, Joule heating rate should also be zero. We make three fits to the data. The first fit is to all data, the second fit is to electric fields with values below a given limit and the third fit is to electric fields above the given limit. By looking at data scatter plots, we decided to set the limit as $25 \mathrm{mV} \mathrm{m}^{-1}$ (a value of $40 \mathrm{mV} \mathrm{m}^{-1}$ was also tried). In most cases, the selected limit gives enough statistics also for the larger electric fields.

The results of the fits are presented in Figs. 14-17 and the three fitted functions shown in each figure from top to bottom are to all data, to low electric fields and to high electric fields, respectively. The common feature is that low electric fields are well described by the quadratic relationship in many cases, but for high electric fields the linear coefficients become important. Table 1 summarises the equations that can be used to estimate the Joule heating rate in the four MLT sectors.

We will first look at the midday sector. It is dominated by the solar EUV ionization, which depends on the solar zenith angle (Fig. 3). During the 1-month period the solar zenith angle at noon increases steadily, which produces a small change in the Pedersen conductance. In the midday sector, EISCAT is generally equatorward of the oval and the measured electric fields are rather small. For low activity levels (Fig. 14, left panel), the electric fields are mainly below $25 \mathrm{mV} \mathrm{m}^{-1}$. There are only a couple of electric field values higher than the limit, but they affect considerably the fit of all data (the top equation). Those points exist probably because the 3 -h $K_{p}$ is not able to resolve sudden or short-lived activations. The equation to describe best the midday low-activity case is therefore the middle equation of the plot $\left(E<25 \mathrm{mV} \mathrm{m}^{-1}\right)$ with a quadratic constant of $5.4 \mathrm{~S}$.

Figure 14, right panel, shows a corresponding fit to the high activity data. A quadratic term with a coefficient of $6.4 \mathrm{~S}$ is obtained for low electric fields $\left(E<25 \mathrm{mV} \mathrm{m}^{-1}\right)$. The value is much higher, $10.6 \mathrm{~S}$, for large electric fields, but a significant negative linear term also appears.

In the evening sector in the low activity case (Fig. 15, left panel), the fit to small electric fields and to all values of electric fields give essentially the same relationship, which is described by the quadratic term and a coefficient of about $5.3 \mathrm{~S}$ (the two top equations). By looking at Fig. 3, it is clear that solar ionization still has a strong effect on this data and the value of the coefficient is about the same as for the 09:0015:00 MLT time interval discussed above. The fit for high electric fields includes a positive linear term.

For the high activity case in the evening sector (Fig. 15, right panel), the coefficient of the quadratic term is $9.6 \mathrm{~S}$ for low electric fields, but a negative linear term is included. The number of large electric fields is clearly larger than for the low activity case and the fit includes a negative linear term.

In the midnight sector, a number of high electric fields are observed for the low activity level (Fig. 16, left panel). A significant positive linear term exists for large electric fields. The high-activity case for low electric fields is almost quadratic with a coefficient of $10.4 \mathrm{~S}$ (Fig. 16, right panel), 

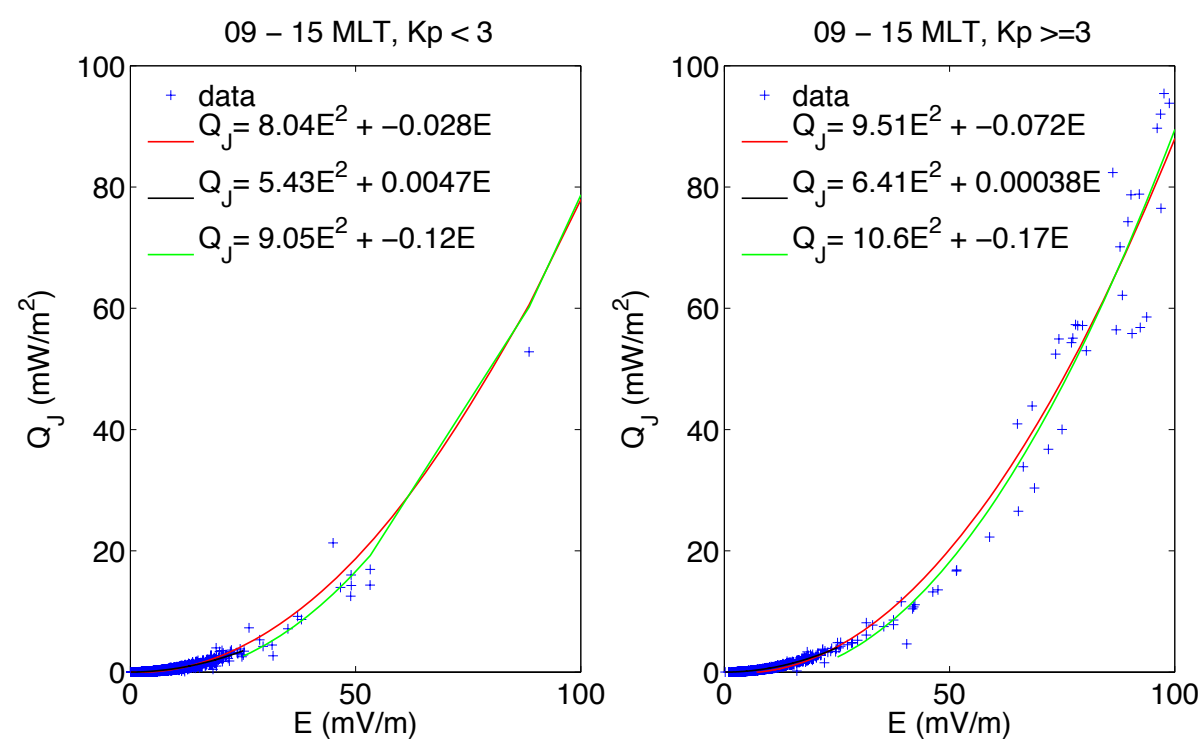

Fig. 14. Joule heating rate vs. total electric field in the midday sector for low ( $K_{p}=0-2$, left $)$ and high $\left(K_{p} \geq 3\right.$, right $)$ activity levels. Three fits to data (+) are shown: the red curve for all data (first equation in the legend), the black curve to low electric fields (second eq.) and the green curve (third eq.) for high electric fields with the limit as $25 \mathrm{mV} \mathrm{m}^{-1}$.
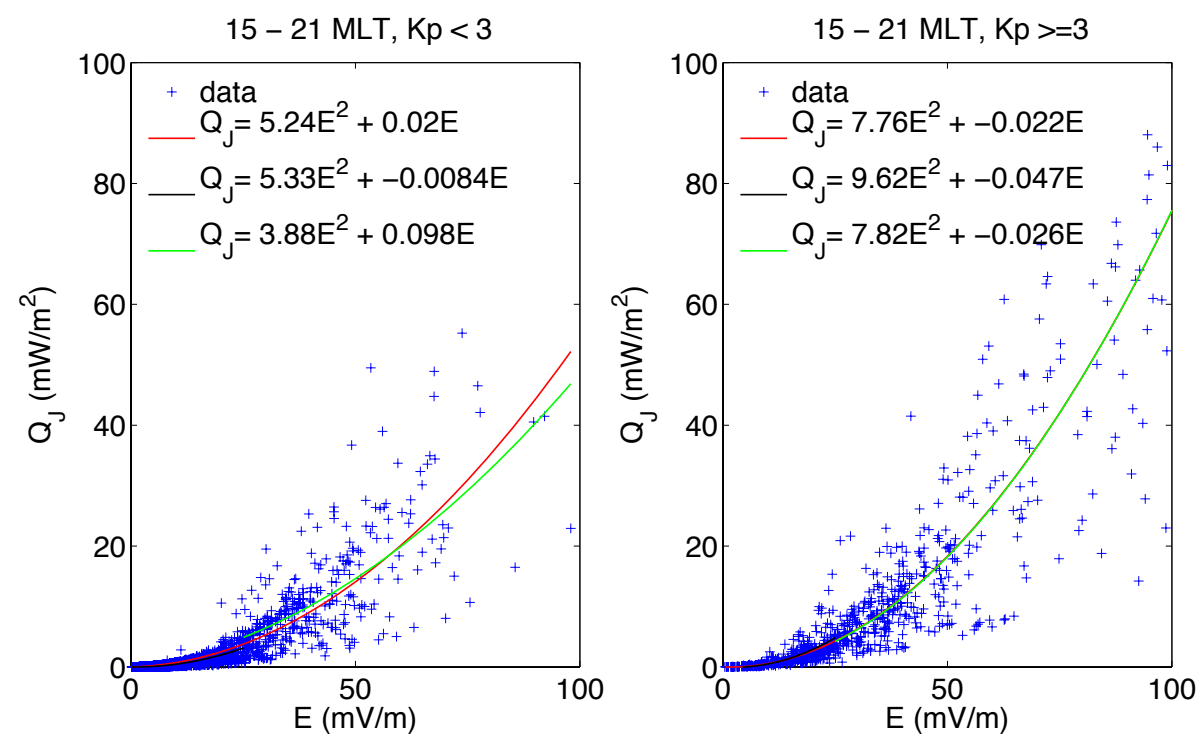

Fig. 15. Same as Fig. 14, but in the evening sector.

but the fit for high electric fields includes a large positive linear term, like the low activity case.

Low activity level in the morning sector (Fig. 17, left panel) is associated with the smallest coefficients obtained: $2.95 \mathrm{~S}$ for low electric fields and $1.7 \mathrm{~S}$ for high electric fields, with insignificant linear terms. The fit to high electric fields is problematic, since the data seems to be bifurcated into two parts and the fit goes in the middle of these two populations. The lower population would correspond even to a lower coefficient.
High-activity morning sector (Fig. 17, right panel) is distinctively different from the low-level morning sector: here the highest constants, $8.7 \mathrm{~S}$ and $11.9 \mathrm{~S}$, are found. However, negative linear terms exist.

To understand better the role of positive and negative linear terms we study the fitted function $q_{j}=A E^{2}+B E$. Without coefficient $B$, we would fit the data to an average Pedersen conductance value represented by the coefficient $A(>0)$. The meaning of the linear term can be understood better, if we write $q_{j}=\left(A+\frac{B}{|E|}\right) E^{2}=\Sigma_{P}^{\text {eff }} E^{2}$. Now, 

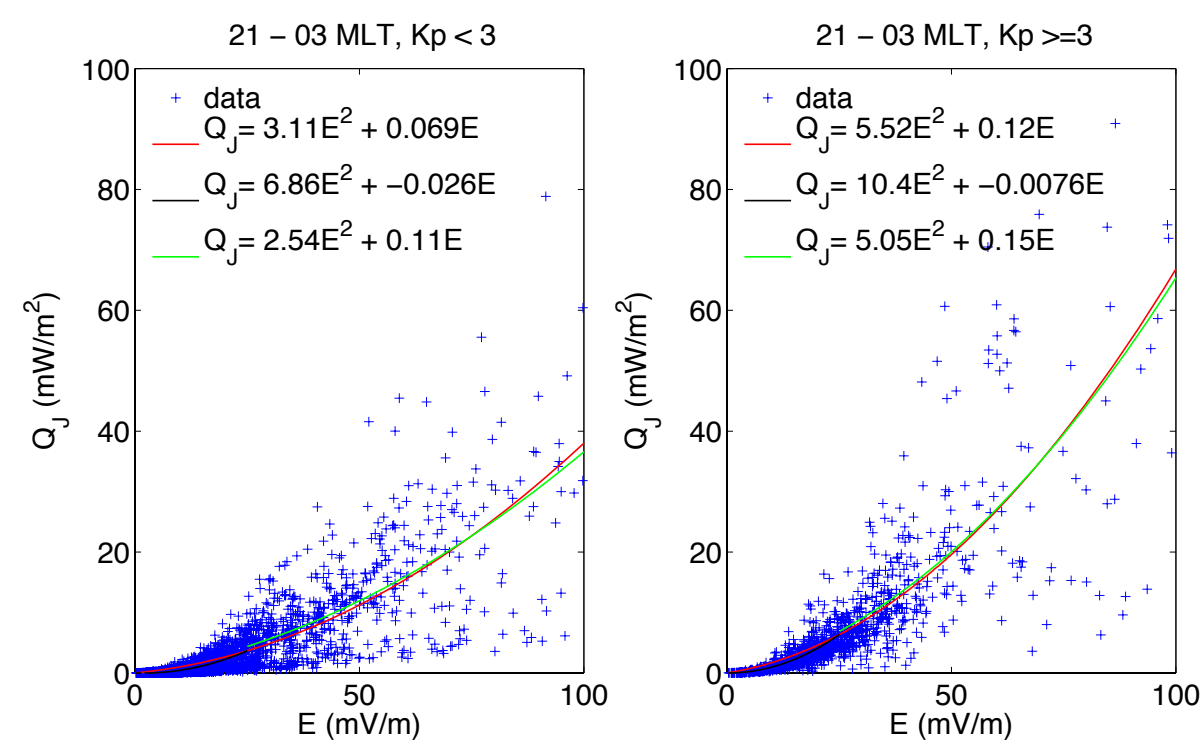

Fig. 16. Same as Fig. 14, but in the midnight sector.
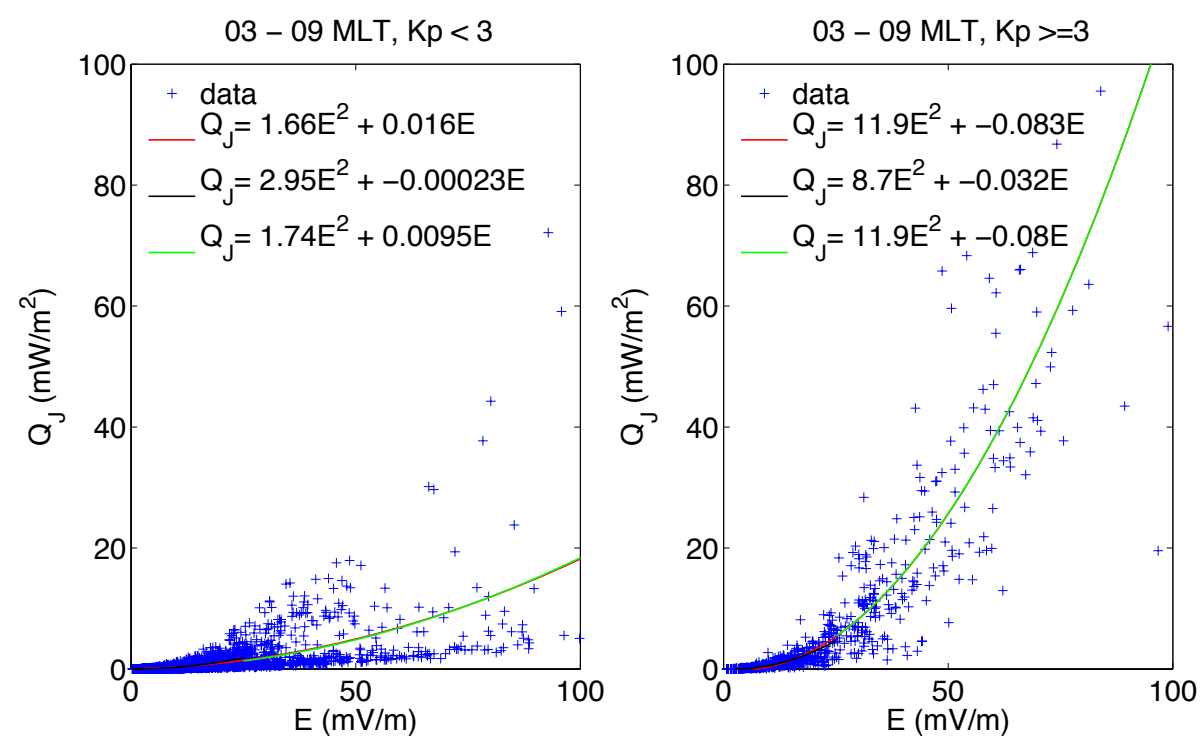

Fig. 17. Same as Fig. 14, but in the morning sector.

if $B>0$, then $\Sigma_{P}^{\text {eff }}=A+\frac{|B|}{|E|}$. We are here mainly interested in data with $|E|>25 \mathrm{mV} \mathrm{m}^{-1}$, so $E_{\min }=25 \mathrm{mV} \mathrm{m}^{-1}$ corresponds to a maximum in effective conductance $\Sigma_{P}^{\text {eff }}$. When the magnitude of the electric field increases, the effective conductance decreases. So, for a positive fit coefficient $B$, we get anticorrelation between electric field and conductance. On the other hand, if $B<0$, then $\Sigma_{P}^{\text {eff }}=A-\frac{|B|}{|E|}$. Now, $E_{\min }$ corresponds to a minimum in effective conductance and by increasing $|E|$ we increase $\Sigma_{P}^{\text {eff }}$. The positive value of $B$ allows correlation between electric field and the effective conductance. Hence, by finding the best fit to the function in question, we can get $B=0$ (constant Pedersen conductance for all electric field values), $B$ negative (correlation between electric field and conductance), or $B$ positive (anticorrelation between electric field and conductance).

The physical reason behind anticorrelated conductance and electric field can be understood as follows. If the ionosphere plays an active role in the magnetosphere-ionosphere coupling, electric fields may be enhanced to rather high values in regions of low conductances located adjacent to auroral arcs, to facilitate current flow. This has been often called as the arc-associated electric field (e.g. Aikio et al., 1993, 2004). On the other hand, polarization electric fields may 

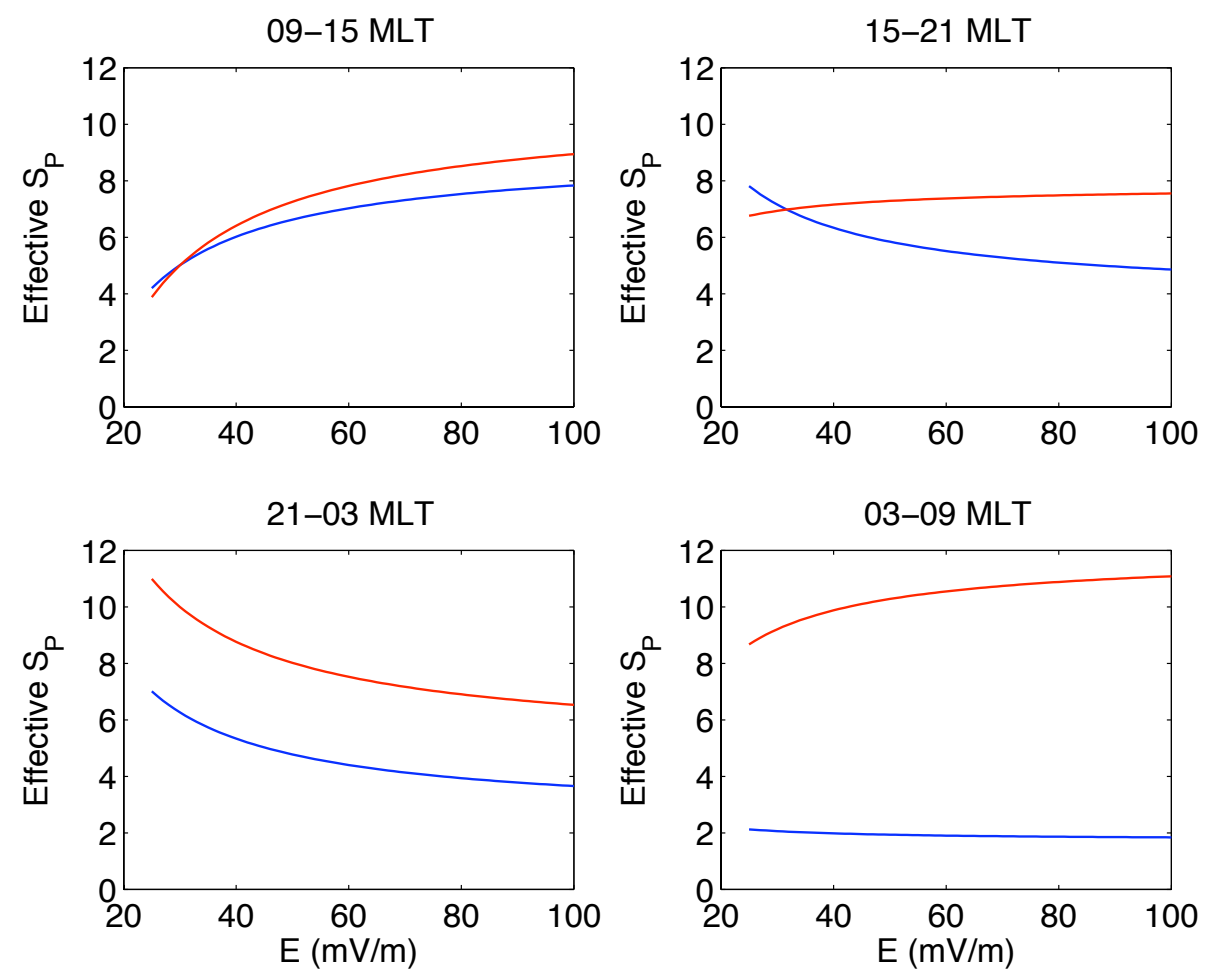

Fig. 18. Effective conductance as a function of electric field magnitude in the four MLT sectors. The blue curve is for $K_{p}<3$ and the red curve for $K_{p} \geq 3$.

arise in high-conductance regions if field-aligned currents are inhibited from flowing and thus the total electric field value may be decreased, producing anticorrelation for low electric field values.

If electric field and conductance are correlated, obviously the effects discussed above are not important, but a rise in magnetic activity is associated with both increased conductances and electric field values.

Figure 18 presents the effective conductance $\Sigma_{P}^{\text {eff }}$ for electric fields larger than $25 \mathrm{mV} \mathrm{m}^{-1}$ in the four MLT sectors and for low (blue line) and high (red line) activity levels. In the day sector 09:00-15:00 MLT, electric field magnitude and conductance are correlated. In the midnight sector 21:0003:00 MLT, anticorrelation is observed both for low and high activity levels. The conductance values at $25 \mathrm{mV} \mathrm{m}^{-1}$ (7 and $11 \mathrm{~S})$ are about the same as for low electric fields with corresponding activity levels, so here we have decreased conductances associated with enhanced electric fields, probably associated with ionospheric density cavities and regions adjacent to auroral arcs.

In the evening sector 15:00-21:00 MLT, the low activity curve resembles that of the midnight sector, but a little surprisingly, the high activity conductance is almost independent of electric field. We have done the same calculations by using $K_{p}=4$ as the limit (not shown) instead of $K_{p}=3$ and then we get anticorrelation in the evening sector for both activity levels. Behaviour in the other sectors remains unchanged.

In the morning sector 03:00-09:00 MLT, the low and high activity curves are very different. The low activity curve is constant with a value of $2 \mathrm{~S}$, whereas the high activity curve behaves like that in the day sector: small increase of conductance with electric field. The value is the highest of all sectors, in accordance with the measured Pedersen conductance values in this sector.

\section{Conclusions}

Below, we will shortly summarize the most interesting results related to Joule heating based on a statistical analysis of one month of EISCAT data near vernal equinox with good spatial and temporal resolution at a corrected geomagnetic latitude of $66.6^{\circ}$. Detailed characteristics of conductances and electric fields are discussed in the previous sections.

Our results indicate that the response of morning sector conductances and conductance ratios to increased magnetic activity is stronger than that of the evening sector. Juusola et al. (2007) found the same effect for conductance ratios, but e.g. the Hardy et al. (1987) conductance model doesn't reproduce this effect. The co-location of Pedersen conductance maximum and electric field maximum in the morning sector produces the largest Joule heating rates between 03 
and 05 MLT for $K_{p} \geq 3$ in this study. The result is in accordance with AMIE model results by McHarg et al. (2005), but the study by Weimer (2005) show equal Joule heating rates in the evening and morning sectors. Modeling efforts have suggested that the dawn-dusk asymmetry is enhanced by the neutral wind effect: the difference between ion and neutral velocities due to ion drag and Coriolis force is larger on the dawnside than on the duskside (Thayer et al., 1995; Deng and Ridley, 2007).

Between the evening and morning Joule heating maxima, a local minimum at 23 MLT is observed. The minimum coincides with the electric Harang discontinuity. The midnight minimum has been found also in several earlier studies, of variable width (Fujii et al., 2000; Chun et al., 2002; McHarg et al., 2005; Weimer, 2005).

Fits to Joule heating rates as a function of electric field in the four MLT sectors were performed. In addition to the squared electric field term, the fit included a linear term to study the possible anticorrelation or correlation between the electric field and conductance. In the midday sector, positive correlation was found as well as in the morning sector for the high-activity case. In the midnight and evening sectors, anticorrelation between electric field and conductance was obtained, i.e. high electric fields were associated with low conductances. This is expected to occur in the return current regions adjacent to auroral arcs as a result of ionospheremagnetosphere coupling, as discussed by Aikio et al. (2004). In addition, a part of the anticorrelation may come from polarization effects inside high-conductance regions, e.g. auroral arcs.

These observations confirm the speculated effect of small scale electrodynamics, which is not included in most of the global modeling efforts of Joule heating rate. Palmroth et al. (2005) argue that spatial anticorrelation of electric field and Pedersen conductance leads to the overestimation of Joule heating, if averaged measurements are used. On the other hand, if small-scale structures (e.g. intense localized electric fields) are totally absent from the models, this leads to underestimation of Joule heating rates, as discussed by Deng and Ridley (2007).

It is obvious that Joule heating rates depend on magnetic activity (driven by the IMF parameters), but seasonal effects are also likely to be important. Juusola et al. (2007) showed that the largest conductance ratios occur for winter, then equinox and last summer. Schlegel (1988) found that conductances are higher in the winter than in summer; both studies were for the Northern Hemisphere. Olsson et al. (2004) obtained different formulas for global Joule heating estimates during summer, equinox and winter. Clearly a larger database with simultaneous high spatial and temporal resolution electric field and conductance measurements would be needed in order to discern all the effects discussed above affecting the Joule heating rate. In addition, neutral wind altitude profiles would be needed so that the dynamics of the neutral atmosphere could be taken into account.
Acknowledgements. We thank R. Kuula for the help in analysing the data and T. Nygrén for useful discussions. EISCAT is an international association supported by China (CRIRP), Finland (SA), Japan (STEL and NIPR), Germany (DFG), Norway (NFR), Sweden (VR) and United Kingdom (STFC).

Topical Editor M. Pinnock thanks M. G. McHarg and another anonymous referee for their help in evaluating this paper.

\section{References}

Ahn, B. H., Akasofu, S.-I., and Kamide, Y.: The Joule heat production rate and the particle energy injection rate as a function of the geomagnetic indices AE and AL, J. Geophys. Res., 88, 6275-6287, 1983.

Aikio, A. T., Opgenoorth, H. J., Persson, M. A. L., and Kaila, K. U.: Ground-based measurements of an arc-associated electric field, J. Atmos. Terr. Phys., 55, 797-808, 1993.

Aikio A. T., Lakkala, T., Kozlovsky, A., and Williams, P. J. S.: Current systems of stable drifting auroral arcs in the evening sector, J. Geophys. Res., 107(A12), SIA 3-1-SIA 3-14, 2002.

Aikio, A. T., Mursula, K., Buchert, S., Forme, F., Amm, O., Marklund, G., Dunlop, M., Fontaine, D., Vaivads, A., and Fazakerley, A.: Temporal evolution of two auroral arcs as measured by the Cluster satellite and coordinated ground-based instruments, Ann. Geophys., 22, 4089-4101, 2004, http://www.ann-geophys.net/22/4089/2004/.

Brekke, A. and Hall, C.: Auroral ionospheric quiet summer time conductances, Ann. Geophys., 6, 361-376, 1988.

Chun, F., Knipp, D., McHarg, M., Lu, G., Emery, B., Vennerstrøm, S., and Troshichev, O.: Polar Cap Index as a Proxy for Hemispheric Joule Heating, Geophys. Res. Lett., 26, 1101-1104, 1999.

Chun F. K., Knipp, D. J., McHarg, M. G., Lacey, J. R., Lu, G., and Emery, B. A.: Joule heating patterns as a function of polar cap index, J. Geophys. Res., 107, 1119, doi:10.1029/2001JA000246, 2002.

Davies, J. A. and Lester, M.: The relationship between electric fields, conductances and currents in the high-latitude ionosphere: a statistical study using EISCAT data, Ann. Geophys., 17, 43-52, 1999, http://www.ann-geophys.net/17/43/1999/.

Deng, Y. and Ridley, A. J.: Possible reasons for underestimating Joule heating in global models: E field variability, spatial resolution, and vertical velocity, J. Geophys. Res., 112, A09308, doi:10.1029/2006JA012006, 2007.

Foster, J. C., St.-Maurice, J.-P., and Abreu, V. J.: Joule heating at high latitudes, J. Geophys. Res., 88, 4885-4896, 1983.

Fujii, R., Nozawa, S., and Buchert, S.: Statistical characteristics of electromagnetic energy transfer between the magnetosphere, the ionosphere, and the thermosphere, J. Geophys. Res., 104, 23572365, 1999.

Fujii, R., Nozawa, S., Buchert, S. C., and Brekke, A.: Energy coupling between the magnetosphere, ionosphere and thermosphere, Adv. Space Res., 25, 213-218, 2000.

Hardy, D. A., Gussenhoven, M. S., Raistrick, R., and McNeil, W. J.: Statistical and functional representation of the pattern of auroral energy flux, number flux and conductivity, J. Geophys. Res., 92, 12275-12294, 1987.

Juusola, L., Amm, O., Kauristie, K., and Viljanen, A.: A model for estimating the relation between the Hall to Pedersen conductance 
ratio and ground magnetic data derived from CHAMP satellite statistics, Ann. Geophys., 25, 721-736, 2007,

http://www.ann-geophys.net/25/721/2007/.

Kosch, M. J. and Nielsen, E.: Coherent radar estimates of average high-latitude ionospheric Joule heating, J. Geophys. Res., 100, 12201-12215, 1995.

McHarg, M., Chun, F., Knipp, D., Lu, G., Emery, B., and Ridley, A.: High-latitude Joule heating response to IMF inputs, J. Geophys. Res., 110, A08309, doi:10.1029/2004JA010949, 2005.

Moen, J. and Brekke, A.: On the importance of ion composition to conductivities in the auroral ionosphere, J. Geophys. Res., 95, 10687-10693, 1990.

Østgaard, N., Germany, G., Stadsnes, J., and Vondrak, R. R.: Energy analysis of substorms based on remote sensing techniques, solar wind measurements, and geomagnetic indices, J. Geophys. Res., 107, 1233, doi:10.1029/2001JA002002, 2002.

Olsson, A., Janhunen, P., Karlsson, T., Ivchenko, N., and Blomberg, L. G.: Statistics of Joule heating in the auroral zone and polar cap using Astrid-2 satellite Poynting flux, Ann. Geophys., 22, 41334142, 2004, http://www.ann-geophys.net/22/4133/2004/.

Palmroth, M., Janhunen, P., Pulkkinen, T. I., Aksnes, A., Lu, G., Østgaard, N., Watermann, J., Reeves, G. D., and Germany, G. A.: Assessment of ionospheric Joule heating by GUMICS-4 MHD simulation, AMIE, and satellite-based statistics: towards a synthesis, Ann. Geophys., 23, 2051-2068, 2005, http://www.ann-geophys.net/23/2051/2005/.

Picone, J. M., Hedin, A. E., Drob, D. P., and Aikin, A. C.: NRLMSISE-00 empirical model of the atmosphere: Statistical comparisons and scientific issues, J. Geophys. Res., 107, 1468, doi:10.1029/2002JA009430, 2002.

Richmond, A. D. and Kamide, Y.: Mapping electrodynamic features of the high-latitude ionosphere from localized observations: Technique, J. Geophys. Res., 93, 5741-5759, 1988.

Risbeth, H. and Williams, P. J. S.: The EISCAT ionospheric radar: The system and its early results, Q. J. R. Astr. Soc., 26, 478-512, 1985.
Rodger, A. S., Wells, G. D., Moffett, R. J., and Bailey, G. J.: The variability of Joule heating, and its effects on the ionosphere and thermosphere, Ann. Geophys., 19, 773-781, 2001, http://www.ann-geophys.net/19/773/2001/.

Ruohoniemi, J. M. and Greenwald, R. A.: Dependencies of high-latitude plasma convection: Consideration of interplanetary magnetic field, seasonal, and universal time factors in statistical patterns, J. Geophys. Res., 110, A09204, doi:10.1029/2004JA010815, 2005.

Schlegel, K.: Auroral zone E-region conductivities during solar minimum derived from EISCAT data, Ann. Geophys., 6, 129138, 1988.

Senior, C.: Solar and particle contributions to auroral heightintegrated conductivities from EISCAT data: a statistical study, Ann. Geophys., 9, 449-460, 1991.

Sugino, M., Fujii, R., Nozawa, S., Buchert, S. C., Opgenoorth, H. J., and Brekke, A.: Relative contribution of ionospheric conductivity and electric field to ionospheric current, J. Geophys. Res. 107, 1330, doi:10.1029/2001JA007545, 2002.

Tanskanen, E., Pulkkinen, T. I., and Koskinen, H. E. J.: Substorm energy budget during low and high solar activity: 1997 and 1999 compared, J. Geophys. Res., 107, 1086, doi:10.1029/2001JA900153, 2002.

Thayer, J. P., Vickrey, J. F., Heelis, R. A., and Gary, J. B.: Interpretation and modeling of the high-latitude electromagnetic energy flux, J. Geophys. Res., 100, 19715-19728, 1995.

Thayer, J. P.: Radar measurements of the electromagnetic energy rates associated with the dynamic ionospheric load/generator, Geophys. Res. Lett., 25, 469-472, 1998.

Weimer, D. R.: Improved ionospheric electrodynamic models and application to calculating Joule heating rates, J. Geophys. Res., 110, A05306, doi:10.1029/2004JA010884, 2005. 